\title{
Use of X-ray microprobe to diagnose bone tissue demineralization after caffeine administration
}

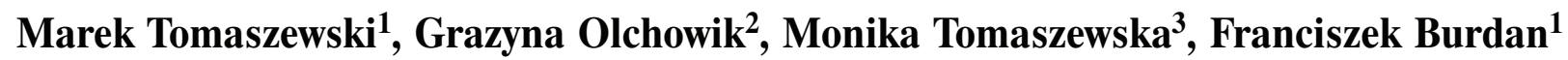 \\ ${ }^{1}$ Department of Human Anatomy, Medical University of Lublin, Poland \\ ${ }^{2}$ Department of Biophysics, Medical University of Lublin, Poland \\ ${ }^{3}$ I Radiology Department, Medical University of Lublin, Poland
}

\begin{abstract}
Caffeine is a methylxanthine which permeates the placenta. In studies on animals, it has been shown to produce teratogenic and embryotoxic effects in large doses. The objective of this study was to assess the influence of caffeine on the development of bone tissue, with particular reference to elemental bone composition using an X-ray microprobe. The research was conducted on rats. The fertilized females were randomly divided into an experimental and a control group. The experimental group was given caffeine orally in $30 \mathrm{mg} / \mathrm{day}$ doses from the $8^{\text {th }}$ to the $21^{\text {st }}$ day of pregnancy, while the control group was given water. The fetuses were used to assess the growth and mineralization of the skeleton. On the basis of double dyeing, a qualitative analysis of the bone morphology and mineralization was conducted. For calcium and potassium analysis, an X-ray microprobe was used. In 67 fetuses from the experimental group, changes in skeleton staining with the alcian-alizarin method were noticed. The frequency of the development of variants in the experimental group was statistically higher. In the experimental group, a significant decrease in the calcium level, as well as an increase in the potassium level, was observed. The X-ray microprobe's undoubted advantage is that is offers a quick qualitative and quantitative analysis of the elemental composition of the examined samples. Employing this new technique may furnish us with new capabilities when investigating the essence of the pathology process. (Folia Histochemica et Cytobiologica 2012, Vol. 50, No. 3, 436-443)
\end{abstract}

Key words: caffeine, bone tissue, rat, X-ray microprobe

\section{Introduction}

Caffeine is commonly found in the food industry and is known to be a central nervous system (CNS) stimulator. It activates the cerebral cortex, improves association processes, and counteracts feelings of tiredness and drowsiness [1-5]. Being an ingredient of coffee and tea, it is a ubiquitous beverage, consumed by all of society. Daily global caffeine consumption is estimated at $3-7 \mathrm{mg} / \mathrm{kg}$ of body mass which is equiva-

\footnotetext{
Correspondence address: M. Tomaszewski, Department of Human Anatomy,

Medical University of Lublin, Jaczewskiego Str. 4, 20-090 Lublin, Poland; e-mail: tomaszewski.marek@gmail.com
}

lent to $200 \mathrm{mg} /$ person/day and depends mostly on dietary habits prevalent in a given region. Average annual consumption amounts to circa $4.5 \mathrm{~kg}$ per person. In the Scandinavian countries, caffeine consumption is higher, e.g. in Finland it reaches $12.2 \mathrm{~kg}$ per person per year [6]. Caffeine consumption has been associated with coronary heart disease, hypertension and adverse reproductive or developmental effects [7]. Olchowik et al. [8] showed that caffeine intake during pregnancy $(30 \mathrm{mg} /$ day) had a negative influence on the bone tissue of female rats.

Of particular interest is the fact that caffeine easily permeates through the placental barrier into the milk of feeding mothers. Repeated attempts have been made to assess the influence of caffeine on embryonic and fetal development. In many experimental works on animals, it has been shown to produce 
teratogenic and embryotoxic effects in large doses. Not all reports have been conclusively confirmed in research on a human population [9-18]. Clinical and epidemic observation, however, indicates that consuming caffeine in doses $>300 \mathrm{mg} /$ day increases the risk of premature pregnancy termination [2, 19, and 20]. Consuming lower doses (around $150 \mathrm{mg} /$ day), in turn, increases the risk of giving birth to a child of low birth weight. The United Kingdom's Food Standards Agency has determined that caffeine consumption of up to $200 \mathrm{mg} /$ day is safe for pregnant women [21].

Pollard et al. [16], Collins et al. [22], Kimmel et al. [23], and Muther [24] paid particular attention to the influence of caffeine on the development of osseous tissue. Among the most frequently described developmental abnormalities are mineralization disorders in the bones of the wrist, metatarsus, phalanges, cranium (parietal, occipital, and interparietal bones) and pubic bones. In the sternum area, administering caffeine caused agenesis of its parts, and in the vertebra, fusion of vertebral bodies, especially in the lumbar and sacral regions. Other researchers [17, 25-27] have analyzed the morphology of developing bones using visual data (obtained with a scanning electron microscope and a transmission electron microscope), and mineral content on the basis of spectrophotometric analysis.

The objective of this study was to assess the influence of caffeine on the development of bone tissue in the rat, with particular reference to elemental bone composition.

In the literature dealing with teratology, no reports have been found on elemental composition analysis using an X-ray microprobe which allows for rapid analysis of a sample's elemental composition. A beam of electrons from a scanning electron microscope excites all the atoms in the scrutinized area of the sample, while the X-ray detector (EDAX) not only identifies all the elements contained within it, but also determines their quantity. Moreover, such analysis enables us to analyze their surface and even their spatial distribution.

\section{Material and methods}

This research was conducted on the basis of the animal experiment model, in compliance with international guidelines for the assessment of developmental toxicity, on white rats of the Wistar strain CRL:(WI)WUBR. The research was conducted with the consent of the Bioethical Board of the Medical University in Lublin.

All the animals were provided with free access to food and water. After a two week acclimatization period, the virgin females, of body mass $238 \pm 24 \mathrm{~g}$, mated overnight with the males (from $8 \mathrm{pm}$ to $8 \mathrm{am}$ ) in a ratio of 5:2. Proof of
Table 1. Characteristics of study groups

\begin{tabular}{|l|c|c|c|}
\hline Group & $\begin{array}{c}\text { Caffeine } \\
{[\mathbf{m g} / \mathbf{k g}]}\end{array}$ & $\begin{array}{c}\text { Number } \\
\text { of females }\end{array}$ & $\begin{array}{c}\text { Number } \\
\text { of fetuses }^{\mathbf{1}}\end{array}$ \\
\hline $\mathrm{E}$ & 120 & 10 & 135 \\
\hline $\mathrm{C}$ & 0 & 10 & 140 \\
\hline
\end{tabular}

${ }^{1}$ Number of fetuses born alive

effective copulation was the presence of spermatozoa or a clot containing a mixture of semen and flaked-off vagina epithelium in the morning vaginal swab (at $8 \mathrm{am}$ ). The fertilized females were randomly divided into two groups of ten specimens, an experimental group (Group E) and a control group (Group C) (Table 1). The day of fertilization was considered to be the first day of pregnancy.

The experiment used caffeine (caffeine anhydrous powder, Sigma-Aldrich ChemieGmbH, Germany) exceeding $99 \%$ purity. The substance was administered in a dose of $30 \mathrm{mg} /$ day, which according to the literature should disturb the rat's prenatal development [22, 24, 27-30].

The substance under investigation was suspended in sterile distilled water at $25^{\circ} \mathrm{C}$ and then a $30 \mathrm{mg}$ /day dose was administered once a day to the Group E females, from the $8^{\text {th }}$ to the $21^{\text {st }}$ day of pregnancy, through a tube inserted into the stomach. The Group C females were given water at an analogous temperature and volume to the ones in Group E. On the $21^{\text {st }}$ day of pregnancy, the pregnant females were killed by decapitation using a specially prepared laboratory guillotine. Death was caused by breaking the continuity of the spinal cord without affecting the continuity of the outer tissue layers. After cutting the covering tissue on the abdominal cavity, the uteri with the fetus were extracted and killed by freezing them in liquid nitrogen (Zaklady Azotowe in Pulawy, Poland). They were then used for skeletal growth and mineralization assessments. A qualitative analysis of the morphology and mineralization of bones was conducted using the principle of double dyeing [31]. The alcian-alizarin method was employed, in which cartilage parts are dyed blue from alcian blue, while the ossified parts are dyed red under the influence of alizarin (Figure 1).

In order to identify the presence of calcium and potassium, ten male fetuses were randomly chosen; one from each litter. Femoral bones were extracted from the fetuses and subsequently frozen in liquid nitrogen. After defrosting, in order to determine the chemical composition, the samples were analyzed with an electron scanning microscope (BS340) using the TESCAN system (TESLA, Czech Republic), combined with an X-ray microprobe (Thermo Electron Corporation, USA). The bone samples first underwent preliminary preparation (cleaning, drying), and then a layer of gold, $10 \mathrm{~nm}$ thick, was evaporation-deposited onto the bones using a Sputron evaporator (Thermo Electron Corporation, USA). An assessment of the chemical composition of the fetal bones was conducted using X-ray spectros- 
copy analysis. The electromagnetic spectra were obtained from the surface of the limb closer to the original point of femoral bone ossification using an X-ray microanalyzer (Thermo Electron Corporation, USA). In order to achieve this, bone samples were 'bombarded' with an electron beam in the scanning chamber of the electron microscope using a $20 \mathrm{kV}$ acceleration voltage. This produced the characteristic $\mathrm{X}$-ray radiation for the atoms in the sample, as a consequence of the electrons dropping from their excited state into their base state. Analysis of the chemical composition, both quantitative and qualitative, was performed using NORAN System SIX Model 300 software.

The spectral fluorescent peaks corresponding to the calcium $\left(\mathrm{Ca}^{2+}\right)$ and potassium $\left(\mathrm{K}^{+}\right)$ions were identified. The sum of the quantities of these elements in the bone was determined to be $100 \%$. In order to achieve unification of the measurement data, identical picture magnifications were selected and the bone fragments were identically positioned with reference to the EDAX detector.

Statistical analysis. The quantitative features were defined by the arithmetic average (mean) and standard deviation (SD).

The distribution of the analyzed features in the group was obtained using the Kolmogorov-Smirnov test. Depending on the distribution value, the significance of the differences among the groups was evaluated using either the $t$-Student test or the U test (Mann-Whitney). The significance of the qualitative features was examined using the $\mathrm{X}^{2}$ test.

For statistical analysis, the STATISTICA 5.0 (StatSoft Inc., USA) computer program was employed. For all the tests, the statistically significant differences were those where the significance co-efficient (p) was less than 0.05 .

\section{Results}

Skeleton morphology was analyzed in 130 fetuses from the group given caffeine (ten litters). In $67 \mathrm{fe}-$ tuses $(51.5 \%)$ from the group exposed to caffeine and in 18 suckling pups $(14.4 \%)$ from the control group, the skeleton was stained differently by the alcian-alizarin method. In the examined population, the development variants with decreased mineralization were dominant, which morphologically corresponds to a reduction in, or a lack of, alizarin staining. The frequency of the development variants in the animals given caffeine was indeed higher, compared to the control group $\mathrm{p}<0.05$ (Table 2 ).

In the cranial area, a reduction in, or a lack of, staining of the parietal, occipital and interparietal bones was most frequently observed (Figure 2).

In the case of parietal bones, mineralization disorders were always characterized as two-sided. A reduction, as well as a lack of staining, was observed only in fetuses exposed to caffeine. In seven fetuses $(8.2 \%)$ there was a reduction, while in five $(5.9 \%)$ there was a complete lack of staining of the parietal bone.

In the group of animals exposed to caffeine, significant statistical differences in the staining of interparietal bones were recorded when compared to the control group. In Group C, a reduction ( $\mathrm{p}<0.05)$ was observed in 22 suckling pups $(25.9 \%)$, while a lack of staining of these bones was observed in 59 fetuses (69.4\%).

In the group given caffeine, disturbances in the mineralization of the sternum segments were observed in $51(60 \%)$ suckling pups (Figure 3$)$. A statistically significant increase in the incidence of partial mineralization of particular sternum segments was recorded in the experimental group ( $\mathrm{p}<0.05)$, while in the control group anomalies relating to this bone did not occur. In single cases, a complete lack of ossification (17.6\%) and other morphology disorders in segments were found to be asymmetrical, divided and vestigial forms $(10.6 \%)$ (Figure 3 ).

Disturbances in the mineralization of the metacarpal, metatarsus and phalanges bones were also observed more frequently in the experimental group (Figure 4). In the experimental group, in 62 cases (72.9\%) a lack of mineralization of two metacarpal bones was observed, while in the control group the same pathology was only found in eight $(10 \%)$ suckling pups. A lack of staining in the two phalanges of the paw was notably more frequent in Group E than in Group C ( $<$ 0.05) (Figure 3). In Group E, these changes were observed in 55 (64.7\%) suckling pups, while in Group C, they were only observed in eight $(10 \%)$. Disturbances in the mineralization of the remaining structures of the axial skeleton were recorded less frequently and were not statistically significant (Table 2).

Fifty five femoral bones from the Group E fetuses and 55 bones from those in Group $\mathrm{C}$ were used to obtain specimens for mineral content assessment. The average calcium and potassium content in the bones of the animals from the control group was $72.88 \%$ and $25.87 \%$ respectively. In the experiment, a significant decrease in the level of calcium $(53.65 \%)$ was observed, as well as an increase in the level of potassium $(46.35 \%)$, in the group of animals whose mothers were given caffeine during pregnancy $(\mathrm{p}<0.05)$ (Figure 5). Figures 6 and 7 show, for two randomly selected fetuses, example visualizations and X-ray spectra of the bone end, closer to the original ossification center in the femoral bones.

\section{Discussion}

Experimental research indicates that caffeine toxicity depends on the way caffeine is given. For a rat $\mathrm{LD}_{50}$, it is $192 \mathrm{mg} / \mathrm{kg}$ for oral administration. The maximum 
Table 2. Incidence of developmental defects and variations in the group exposed to caffeine (Group E) and the control group (Group C)

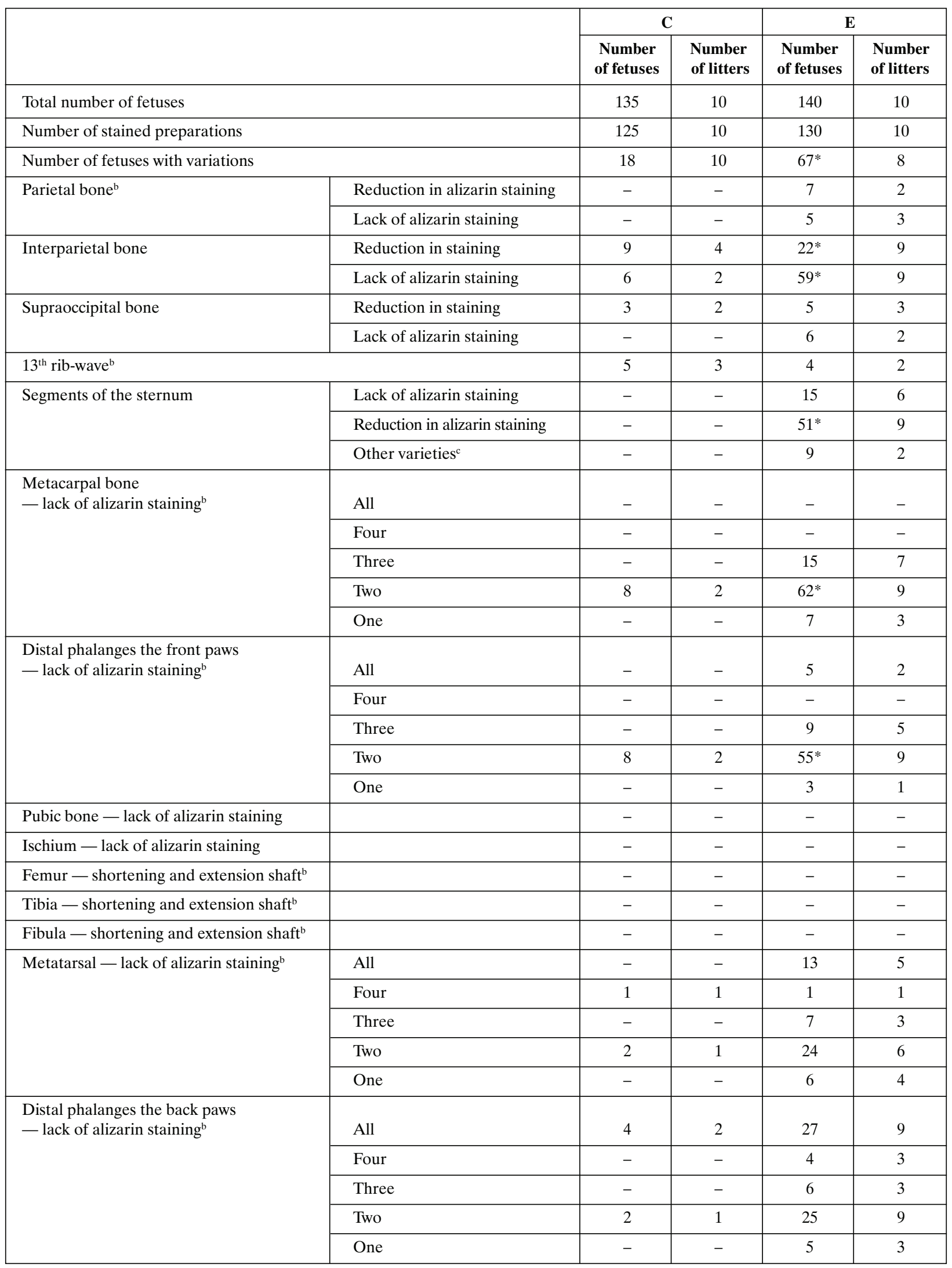

Single fetus may be represented more than once in the above statement; 'single-or double-sided; casymmetrical, split and residual;

*significant changes compared to the control group 

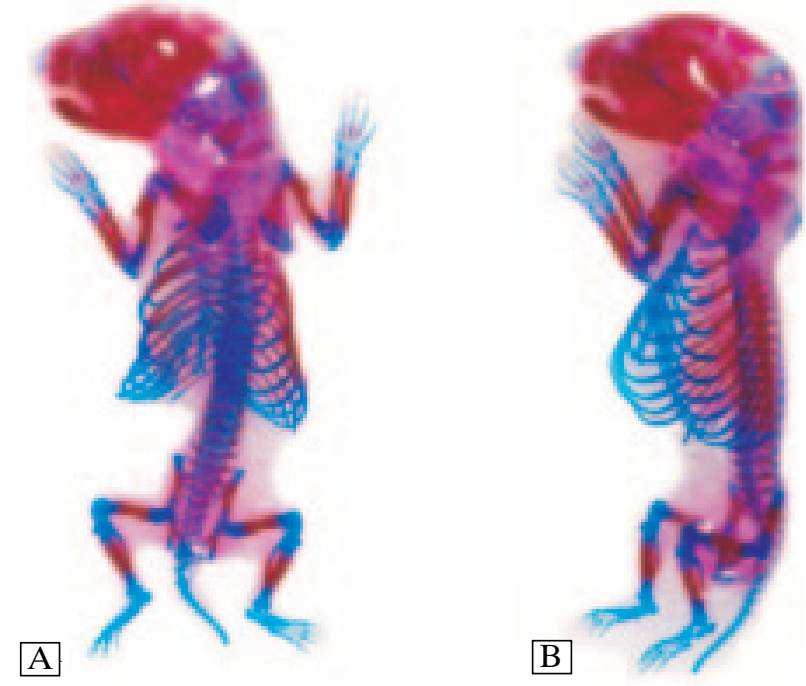

Figure 1. A. Back view skeletal of 21-day fetal rat (Group C), B. side view skeletal of 21-day fetal rat (Group C)
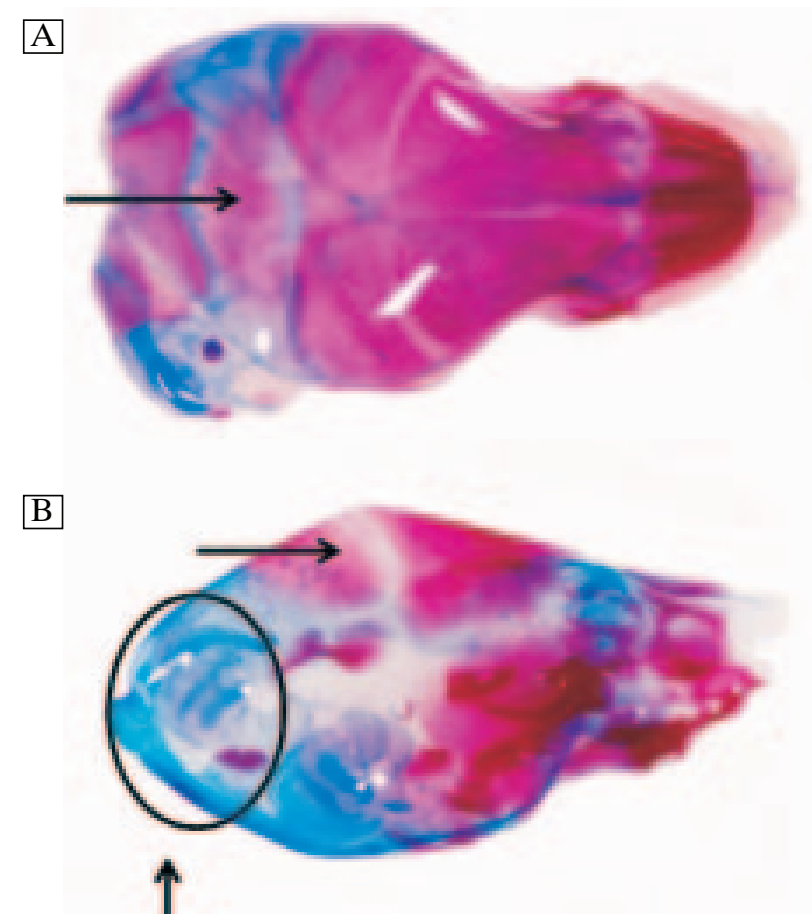

Figure 2. A. Reduced mineralization in intraparietal bone $(\rightarrow)$ (Group E), B. lack of mineralization in intraparietal and supraoccipital bone $(\uparrow)$ and reduced mineralization in parietal bone $(\rightarrow)$ (Group E)

dose of caffeine administered orally to humans is $1.5 \mathrm{~g}$, while a lethal dose is $10-12 \mathrm{~g}$, equivalent to $150 \mathrm{mg} /$ $/ \mathrm{kg}$. In fact, in the literature there are reports of lethal intoxication after ingesting $500 \mathrm{mg}$ of this methyloxanthine. On the other hand, there is also a description of a patient who survived a caffeine intake of $24 \mathrm{~g}$ [20, 32].
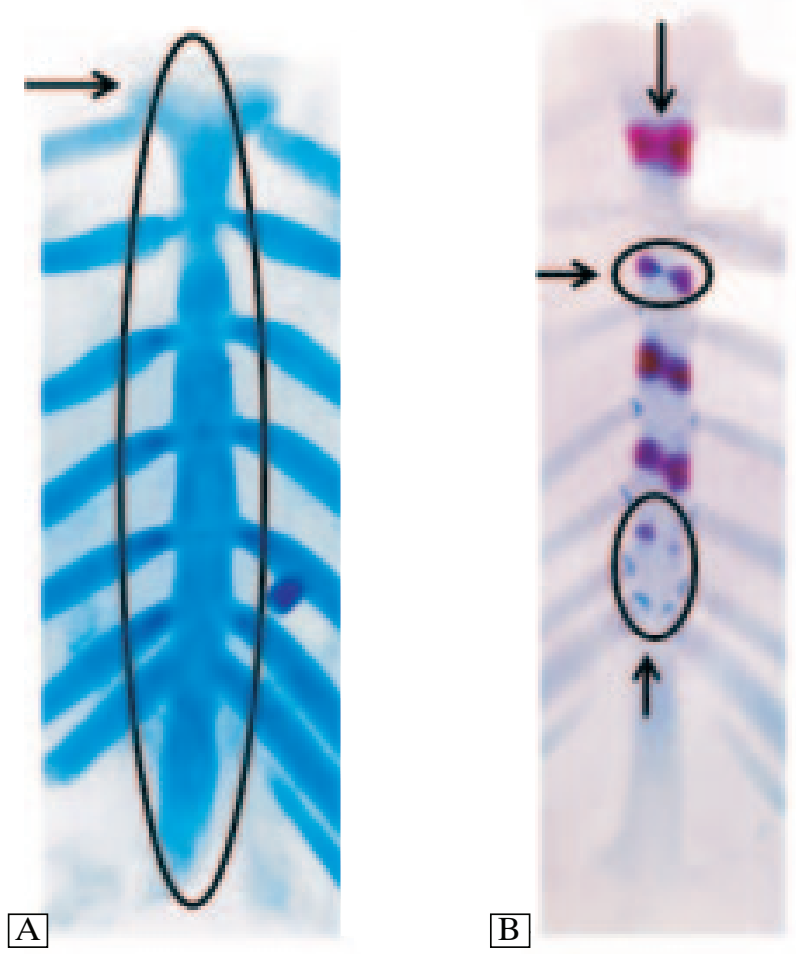

Figure 3. A. Lack of mineralization of the sternum segments $(\rightarrow)$ (Group E), B. asymmetrical $(\downarrow)$, divided $(\rightarrow)$ and residual $(\uparrow)$ segments of sternum (Group E)

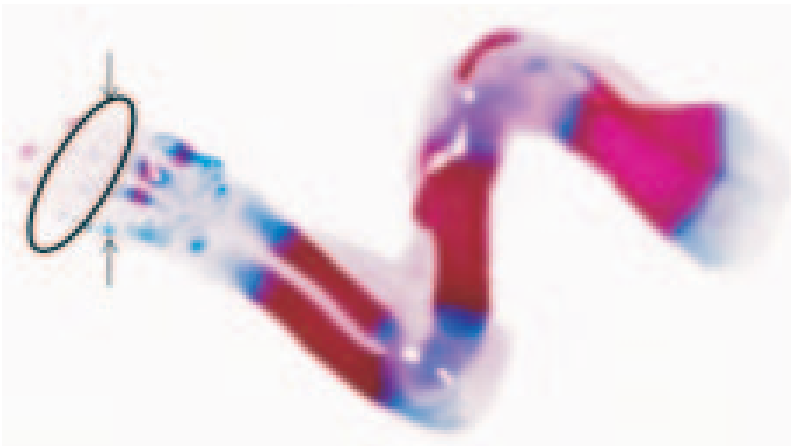

Figure 4. Lack of mineralization in metacarpal bone $(\uparrow)$, proximal and middle phalanges $(\downarrow)$ (Group E)

Caffeine easily permeates through the placental barrier into the milk of feeding mothers [33, 34]. Many attempts have been made to assess the influence of caffeine on embryonic and fetal development. In many experimental studies on animals, the teratogenic and embryotoxic influence of large caffeine doses has been established. Nishimura and Nakai [14] were the first to discover that caffeine in a dose of $250 \mathrm{mg} / \mathrm{kg}$, administered to pregnant mice in a gastrointestinal way, causes abnormalities in the development of the offspring. Split palate and deformations in the digits were observed in $43 \%$ of the offspring whose mothers were given caffeine between the $10^{\text {th }}$ and $14^{\text {th }}$ days of preg- 
nancy. Additionally, Miao et al. [35] found that caffeine had no effect on the quality of oocytes in vivo maturation, but it was detrimental to the quality of oocytes matured in vitro in the mouse model. Al-Saleh et al. [36] found that when caffeine levels in serum increased, the number of eggs decreased, which could be connected with the accumulation of caffeine in the

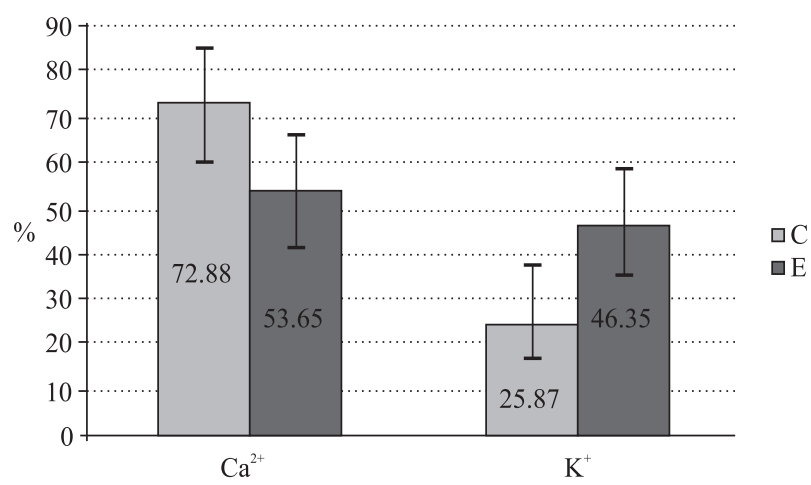

Figure 5. Percentage of the average content of calcium $\left(\mathrm{Ca}^{2+}\right)$ and potassium $\left(\mathrm{K}^{+}\right)$, together with a standard deviation in the fetuses' femurs between groups of animals receiving water (Group C) and caffeine (Group E) (p < 0.05) follicular fluid. Kujawa-Hadryś et al. [37, 38] showed that caffeine causes disturbances in the developing cornea in chicken embryos. Additionally, KujawaHadryś et al. [38] found that caffeine causes changes to the collagen fibers of Bowman's membrane patterns and to the corneal stroma. Moreover, it changes the proportion of the amount of collagen fibers and of the stromal cells in chicken embryos.

Caffeine during pregnancy can disturb the development of the osseous tissue. In our experiment, the commonest abnormalities related to: impaired mineralization of the interparietal bone, two metacarpal bones, two distal phalanges of the front paw, and segments of the sternum. Similar changes, in the form of delayed mineralization, were observed by Smith et al. [39] and Collins et al. [22]. Smith et al. [39] supplied caffeine in a dose of $100 \mathrm{mg} / \mathrm{kg}$, and Giannelli et al. [19] showed disturbed mineralization in animals receiving caffeine in utero in doses of $24.7-29.0 \mathrm{mg} / \mathrm{kg}$. Abnormalities occurred most commonly in the sternum area (incomplete mineralization, complete lack or splitting of the sternum), the ribs (supernumerary intrathoracic or lumbar rib, so-called 'wavy ribs'), and the metatarsus and metacarpal bones (impairment of ossification).
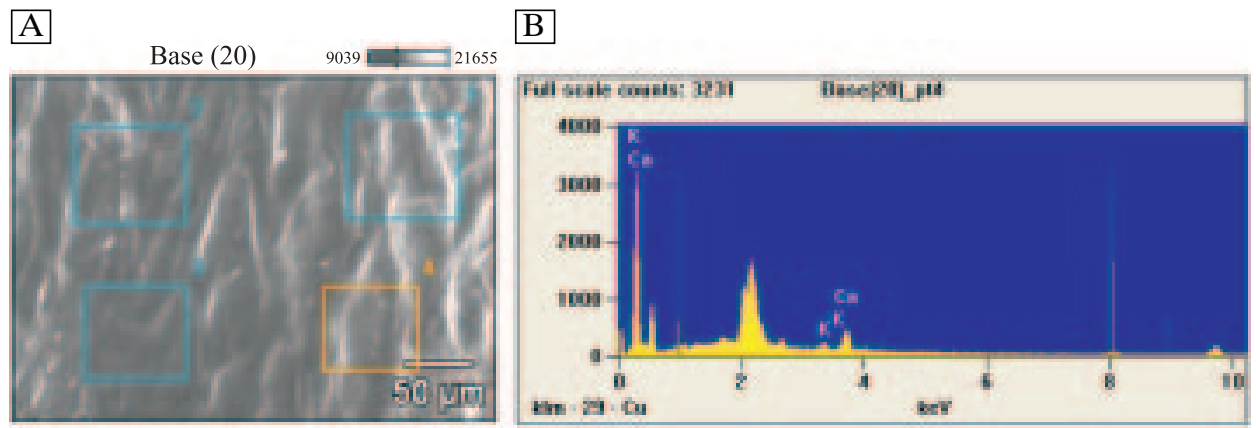

Figure 6. A. Surface of the proximal end of the original nucleus of ossification in the femoral diaphysis of the offspring from the control group (Group C) (SEM, × 200), B. X-ray spectrum of the field marked in orange. In the present case, the percentage of calcium and potassium on the Kenergy level is, respectively, $81.4 \%$ and $18.60 \%$
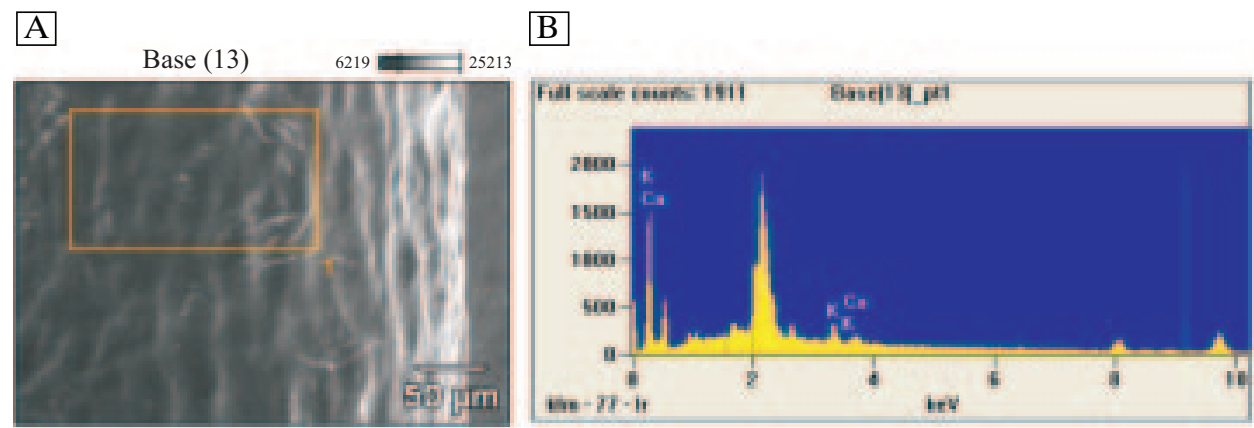

Figure 7. A. Surface of the proximal end of the original nucleus of ossification in the femoral diaphysis of the offspring from the group receiving a solution of caffeine (Group E) (SEM, × 200), B. X-ray spectrum of the field marked in orange. In the present case, the percentage of calcium and potassium on the K energy level is, respectively, $48.71 \%$ and $51.29 \%$ 
Muther [24] showed that the greatest vulnerability of an organism to an ossification disturbance in rats occurs between the $16^{\text {th }}$ and $19^{\text {th }}$ days of pregnancy. In an experiment, he observed reduced ossification in the metatarsus and metacarpal bones. In the group exposed to caffeine $(100 \mathrm{mg} / \mathrm{kg})$ between the $7^{\text {th }}$ and $19^{\text {th }}$ days, similar or smaller changes ensued. On the other hand in the cranial area (the parietal, occipital, interparietal, nasal and frontal bone) as well as in the sternum (agenesis of its particular segments), more intensive changes occurred after prolonged administration of caffeine.

In order to examine mineralization correctly, apart from a morphological examination, it is also necessary to establish the elemental content in the osseous tissue. As a result of our research, performed using an X-ray microprobe, we observed a significant statistical decrease in the calcium content $(53.65 \%)$ $(\mathrm{p}<0.05)$ and an increase in the potassium content $(46.35 \%)(\mathrm{p}<0.05)$ in the group of animals whose mothers were given a $30 \mathrm{mg}$ /day dose of caffeine during pregnancy.

The elemental composition of the developing osseous tissue in animals exposed to the influence of caffeine has also been determined by other authors [17, 25-27, and 40]. Nakamoto et al. [22] fed caffeine to female rats from the $8^{\text {th }}$ to the $22^{\text {nd }}$ day of pregnancy $(0.5-2.0 \mathrm{mg} / \mathrm{kg})$ together with a protein diet. In the groups exposed to the highest dose of the teratogen, they confirmed a decrease in the amount of calcium, phosphates, magnesium and zinc. Sasahara et al. [26] determined the amount of calcium, magnesium and zinc spectrophotometrically, and the phosphate amount using the calorimetric method in rat fetuses exposed to caffeine. Pregnant rats were fed with food containing $20 \%$ protein with caffeine $(20 \mathrm{mg} / \mathrm{kg})$ or caffeine $(20 \mathrm{mg} / \mathrm{kg})$ with zinc $(0.6 \mathrm{~g} / \mathrm{kg})$. They did not determine any significant alterations in the amount of calcium and phosphorus in the femoral bones of the suckling pups from mothers receiving only caffeine compared to the control group animals. They observed, however, significantly higher calcium content in animals with prenatal zinc supplements.

Sasahara [40] described the correlations between caffeine consumption and skeleton ossification. A $20 \mathrm{mg} /$ day dose of caffeine was given to pregnant female rats and then to the suckling pups for the next 93 days. Notable increases in the levels of calcium, phosphates, zinc, magnesium, and hydroxyprolin were observed in the offsprings' femoral bone and mandible. Despite the size of the femur and periosteum being larger compared to the control group, the ossified cross-sectional area, as well as the content of the osteocytes, underwent significant reduction.
Wink et al. [27] determined the histological structure of bones in quickly developing rat suckling pups exposed during pregnancy to caffeine, using a scanning and transmission electron microscope. Pregnant females were given caffeine $(40 \mathrm{mg} / \mathrm{kg}$ ) with a $20 \%$ protein diet. With the use of visualizations obtained using a scanning and transmission electron microscope and a fluorescence microscope, it was found that in young animals, whose mothers were given caffeine, the number of osteocytes in the femoral bone significantly decreased. It was additionally shown that there were abnormal mitochondria in the osteoblasts and osteocytes, with a decrease in the level of copper and zinc in the cytoplasm of these cells.

Duarte et al. [41] described the correlations between caffeine consumption in the early stages of bone healing and the bone density in rats. It was concluded that a high daily caffeine intake body weight/day) may disturb the early stages of bone healing.

\section{Conclusions}

On the basis of our results, it should be stated that caffeine received in large doses during pregnancy disturbs the development of the osseous tissue and its mineralization. It should also be emphasized that the X-ray microprobe can be a perfect complement to the methods enabling us to determine the mineralization of the osseous tissue. These methods include both the traditional ones (alcian-alizarin dyeing) as well as the more modern ones (scanning and transmission microscope, cremation using spectrophotometry). Its undoubted advantage is a quick qualitative and quantitative analysis of the elemental composition of the examined samples. Employing the new technique may furnish us with new capabilities when investigating the essence of the pathology process.

\section{References}

1. Daly JW, Fredholm BB. Caffeine - an atypical drug of dependence. Drug Alcohol Depend. 1998;51:199-206

2. Garattini S, Bonati M, Latini R. Studies on the kinetics and metabolism of caffeine. In: Proceedings of third international caffeine committee workshop. Hunt Valley. Maryland 1980.

3. Graham H.N. Mate. In: Spiller GA. Progress in clinical and biological research. Tom 159. The methylxanthine beverages and foods: chemistry, consumption and health effects. Alan R Liss Press, New York; 1984:179-183

4. PKL 2007. Pharmindex kompendium leków. Medi Media International, Warszawa.

5. Ferre S. An update on the mechanisms of the psychostimulant effects of caffeine. J. Neurochem. 2008;1105:1067-1079.

6. Barone JJ, Roberts H. Caffeine consumption. Food Chem Toxicol. 1996;34:119-129.

7. Cornelis MC, El-Sohemy A. Coffee, caffeine and coronary heart disease. Curr Opin Clin Nutr Care. 2007;10:745-751. 
8. Olchowik G, Chadaj-Polberg E, Tomaszewski M, Polberg M, Tomaszewska M. The influence of caffeine on the biomechanical properties of bone tissue during pregnancy in a population of rats. Folia Histochem Cytobiol. 2011;49:504-511.

9. Bartel H, Mielczarek J. Teratogenne działanie kofeiny na rozwój kończyn u myszy. Gin Pol. 1973;5:507-514.

10. Fadel RAR, Persaud TVN. Effect of alcohol and caffeine on whole rat embryos. Act Anat. 1992;144:114.

11. Gilbert SG, Deborah CR. Somatic development of the infant monkey following in utero exposure to caffeine. Fundam Toxicol. 1991;17:454-465.

12. Gilbert SG, Rice DC, Reuhl KR, Stavric B. Adverse pregnancy outcome in the monkey (Macaca fascicularis) after chronic caffeine exposure. J Pharmacol Exp Ther. 1998;245:1048-1053.

13. Gilbert SG, So Y., Klassen R, Geoffroy S, Stavric B, Rice D. Elimination of chronically consumed caffeine in the pregnant monkey (Macaca fascicularis). J Pharmacol Exp Ther. 1986;239:891-897.

14. Nishimura $H$, Nakai K. Congenital malformations in offspring of mice treated with caffeine.Proc Soc Exp Med. 1960;104:140 -142 .

15. Podlewski K, Chwalibogowska-Podlewska A. Leki wspótczesnej terapii. Wyd. 18. Split Tracling, Warszawa; 2007.

16. Pollard I, Jabbour H, Mehrabani PA. Effects of caffeine administered during pregnancy on fetal development and subsequent function in the adult rat: prolonged effects on the second generation. J Toxicol Environ Health. 1987;22:1-16.

17. Rossowska MJ, Carvajal W, Joseph F, Nakamoto T. Postnatal caffeine effects on copper, zinc and iron concentration in mam mary gland, milk and plasma of lactating dams and their offspring. Ann Nutr Metab. 1997;41:60-65.

18. Scott W. Caffeine - induced limb malformation: description of malformation and quantitation of placental transfer. Teratology. 1983;28:427-435.

19. Giannelli M, Doyle P, Roman E, Pelerin M, Hermon C. The effect of caffeine consumption and nausea on the risk of miscarriage. Paediatr Perinat Epidemiol. 2003;17:316-323.

20. Infante-Rivard C, Fernandez A, Gauthier R, David M, Rivard G-E. Fetal loss associated with caffeine intake before and during pregnancy. JAMA. 1993;270:2940-2943.

21. Food Standards Agency: Food Standards Agency publishes new caffeine advice for pregnant women. London: Food Standards Agency. 2008. Available at: http://www.food.gov.uk/ /news/pressreleases/2008/nov/caffeineadvice. Accessed January 14, 2012.

22. Collins TFX, Welsh JJ, Black TN, Whitby KE, O’Donnell MW Jr. Potential reversibility of skeletal effects in rats exposed in utero to caffeine. Food Chem Toxicol. 1987;25:647-662.

23. Kimmel CA, Laborde JM, Trammell CT. Evaluation of cartilage bone formation in fetal skeletons following prenatal insult normalities not apparent in alizaryn-stained specimens. Teratology. 1982;25:54-55.

24. Muther TF. Caffeine and reduction of fetal ossification in the rat: fact or artifact? Teratology. 1988;37:239-247.
25. Nakamoto T, Grant S, Yazdani M. The effect of maternal caffeine intake during pregnancy on mineral contents of rat bone. Res Exp Med. 1989;189:275-280.

26. Sasahara H, Yamano H, Nakamoto T. Effects of maternal caffeine with zinc intake during gestation and lactation on bone development in newborn rats. Arch Oral Biol. 1990;35:425-430.

27. Wink CS, Rossowska MJ, Nakamoto T. Effects of caffeine on bone cells and bone development in fast-growing rats. Anat Rec. 1996;246:30-38.

28. Burdan F. Teratogenic and embriotoxic effects of caffeine: facts and hypoteses. Pol Merkur Lekarski. 2000;9:726-728.

29. Elmazar MMA, McElhatton PR, Sullivan FM. Studies on the teratogenic effects of different oral preparations of caffeine in mice. Toxicology. 1982;23:57-71.

30. Hart AD, Grimble RF. Effect of methylxanthines on lactational performance of rats. Ann Nutr Metab. 1990;34:297-302.

31. Burdan F. Comparison of developmental toxity of selective and non-selective cyclooxygenase-2 inhibitors in CRL:(WI)WUBR Wistar rats - DFU and piroxicam study. Toxicology. 2005;211:12-25.

32. Kerrigan S, Lindsey T. Fatal caffeine overdose: two case reports. Forensic Sci Int. 2005;153:67-69.

33. Christian MS. Test methods for assessing female reproductive and developmental toxicology. In: Hayes A.W. Principles and method of toxicology. Wyd. 4. Taylor and Francis. Philadelphia; 2001:1301-1381.

34. Christian MS, Brent RL. Teratogen update: Evaluation of the reproductive and developmental risks of caffeine. Teratology. 2001;64:51-78.

35. Miao YL, Shi LH, Lei ZL et al. Effects of caffeine on in vivo and in vitro oocyte maturation in mice. Theriogenology. 2007;68:640-645.

36. Al-Saleh I, El-Doush I, Grisellhi B, Coskun S. The effect of caffeine consumption on the success rate of pregnancy as well various performance parameters of in vitro fertilization treatment. Med Sci Monit. 2010;16:598-605.

37. Kujawa-Hadryś M, Tosik D, Bartel H. Changes in thickness of each layer of developing chicken cornea after administration of caffeine. Folia Histoch Cytobiol. 2010;48:273-277.

38. Kujawa-Hadryś M, Tosik D, Bartel H. Ultrastructural changes in the developing chicken cornea following caffeine administration. Folia Histoch Cytobiol. 2010;48:371-376.

39. Smith SE, McElhatton PR, Sullivan FM. Effects of administering caffeine to pregnant rats either as a single daily dose or as divided doses four times a day. Food Chem Toxicol. 1987;25:125-133.

40. Sasahara H, Cheuk SL, Wink CS, Hashimoto K, Rossowska MJ, Nakamoto T. Alteration of femoral structure in later life by chronically feeding caffeine during rapid growing period in newborn female rats. Toxicol Lett. 1994;73:55-64.

41. Duarte PM, Marques MR, Bezerra JP, Bastos MF. The effects of caffeine administration on the early stage of bone healing and bone den sity: A histometric study in rats. Archives of oral biology. 2009;54:717-722.

Submitted: 15 November, 2011 Accepted after reviews: 22 February, 2012 